Journal of Development and Communication Studies, Vol. 7. Nos. 1 \& 2, January- December, 2020 ISSN (Online \& Print): 2305-7432.

http://www.devcomsjournalmw.org

\title{
Engaging the disengaged: Examining the domestication of mobile telephony among older adults in Trans-Nzoia and Bungoma Counties in Western Kenya
}

Leah Jerop Komen, Daystar University, Nairobi, Kenya. Email: lkomen@daystar.ac.ke or ledavid2002@gmail.com

\begin{abstract}
The world is growing older. Considering the increasing number of older adults, it is imperative to consider how technology design can meet the needs and wants of these important user groups. Mobile phones offer great potential in improving quality of life for older adults in areas of, healthcare, independent living, communication and reduced isolation. There have been numerous studies on technology design for older adults (Fisk, Rogers, Charness, Czaja, \& Sharit, 2004), but much of the work has focused on indoor and stationary applications such as desktop computers (Zajicek \& Brewster, 2004). Although older people need support beyond stationary situations inside and outside their homes (Goodman, Brewster, \& Gray, 2004), limited number of mobile functions are used by older adults due to high cost associated with mobile phones (Lee: 2007). Conversely, Nimrod (2015), argues older people use mobile phones extensively but little is known about relevant domestication processes involved and the extent to which older adults adopt and use mobile phones. This study interviewed 40 older retired civil servants aged 60 years and above in Western Kenya. Using domestication theory, this study examined the appropriation (Possession and ownership), Objectification (meaning and symbols), incorporation of mobile phones in older people's everyday life and conversion (unintended uses) process of the domestication of mobile technology by the said group. Findings showed that mobile phones both enhanced closeness with their children and isolated them from them too. Majority felt mobile phones had become their 'extended family members' bringing the news of the world to them via mobile phone calls and texts. However, the small font size of texts and the fact that phones were getting smaller in size made it difficult to use. Their favourite mobile phone application was the mobile money locally dubbed Mpesa as they could now receive cash transfers from the government.
\end{abstract}

Key words: older adults, mpesa, isolation, connection, e-inclusion, domestication, Kenya https://doi.org/10.4314/jdcs.v7i1-2.2

(C) 2020. The author. This work is licensed under the Creative Commons Attribution 4.0 International License (CCBy-NC-ND). Users may freely share and redistribute this work provided that the author and the Journal of Development and Communication Studies are fully acknowledged. Users may not tweak or remix and offer this work for sale. The full license may be accessed at https://creativecommons.org/licenses/by-nc-nd/4.0/ 


\section{Introduction}

The World's population is rapidly ageing (UN report, 2015), with the World population prospects predicting a further increase that is poised to double by 2050 to 2.1 billion for persons aged 60 and above. It is also observed that this ageing population is growing faster than the younger age groups. Such a growing number will certainly have a bearing on almost all aspects of the society, economically, socially, matters of housing and well as family strains. Knowing how to cater for this group is not only timely but crucial. One way of meeting the needs of such a category of persons is through the exploitation of the benefits that technology such as mobile telephony presents.

Statistical reports indicate that mobile phones are ranked high on the list of technology items used extensively by older adults. For instance in the United states and many Europeans countries 80\% of individuals over 65 years old use mobile phones (Petrovcic, Fortunati, Vehovar, Kavcic \& Dolnicar, 2015; Smith, 2014) and yet these researchers also observe that little is known about the processes of mobile phone domestication by older adults. It is therefore imperative to consider how technology design can meet the needs and wants of this important user group. Mobile phones in particular offer great potential in improving the quality of life in the areas of healthcare, independent living, communicating with family and need for reduced isolation (Nimrod, 2015). Studies so far have looked at technology design for older persons more often on indoor and stationary applications such as desktop computers. However, older people need support beyond the stationery places to mobile situations inside and outside their homes; otherwise they stand the risk of isolation. According to Helsper (2008), technological forms of exclusion are a reality for significant segments of the population and for some technologies reinforce already deeper existing disadvantages. This paper presents findings of a study conducted in Trans-Nzoia and Bungoma counties in Kenya. It involved a census of 40 members-self formed group of former civil servants through group interviews and focus group discussions. All data was audio recorded and later transcribed and analysed as per domestication of technology theory which was the study's theoretical framework

\section{Literature Review: Domestication despite digital divide}

Digital divides have been considered mostly as a problem of access or presence of dismal use. Hence the famous cliché the have's and have-not's. However, in the recent past, there is a growing contribution by researchers suggesting that the problem is no longer a case of one divide whether information or technology or whatever else may be but rather multiple, complex, multi-layered divides with some coinciding (Livingstone \& Helsper, 2007; Van Dijk, 2005; Goggin, 2013; Donner, 2008; Ling, 2004).They further posit that with devices becoming more cheaper, more and more households can now have access, with material access barriers now becoming less and less (Marien, 2007; Van Dijk, 2005; Komen, 2016). It is against this backdrop that scholars elsewhere have suggested a change of term from digital divide to digital inequality or e-inclusion suggesting that the change connotes or evokes more positive connotation,(Van Dijk, 2005; Brotcorne et al., 2010, Selwyn, 2004). However, I contend that whichever strand 
one takes, there is an undeniable presence of imbalance in the access and utility of technology based on several factors that could be socio-cultural, economic, political, religious or even contextual.

It has been suggested that mobile phones offer seniors or older adults with a wide range of benefits that could be clustered into: psychological, physical and practical (Nimrod, 2016). Psychologically, mobile phones help older adults to stay connected with others such as children, grandchildren, and friends (Oksman, 2006: Nimrod, 2016), in terms of physical benefits, it has been noted that mobile phones help older adults particularly in health management (Joe \& Demiris, 2013; Lee \& Carlisle, 2011) as well as in disease self-management (Amstrong, Nugent, Moore \& Finlay, 2010). The practical benefits of mobile phones have been noted to include daily support for instance navigation and memory aids (Kurniawan, 2008; Massimi \& Baecker, 2007). Despite these benefits, challenges have also been noted to abound. For instance, it is argued that older adults lack mobile literacy skills to help them manipulate technology for their everyday life (Hocky, 2012; Smith, 2014), the designers have neglected this group bringing about problems involving ergonomics and usability (Chen, chan \& Tsang, 2013).Some of the reasons cited for usage of mobile technology by older persons of Saudi Arabia include convenience and ease of use (Khawaji, 2017) which contrasted with Lee's (2007) study that revealed that seniors used a limited number of functions on their phones either because of perceived complexity or failing to see its benefits. Other concerns cited in other studies include unhelpful functions and concerns about older people's security (Mitzner et al., 2010). In another study to establish the use of smart phones by older persons in Spain, Rosales and Fernandez-Ardevol (2016) found that although many older people were adopting the use of smart phones, the smart phone application usage declined with age.

\section{Domesticating mobile phones for older persons}

Domestication of technology is really a negotiation between users, artefacts and social contexts (Haddon, 2003; Silverstone et al, 1992), with user needs contributing largely to its domestication and appearing to have dealt with digital divide across ages (Haddon, 2006; Lee, 2007; Komen, 2016). However, seniors or older adults use limited information communication technologies (ICTS) therefore introducing another divide beyond the digital. Shultz et al (2014) have named this divide, age divide, while others, such as Friemel, 2014; Smith, 2014; Nimrod, 2018) have called it the grey divide, that seem to suggest the older adults are homogeneous.

Several models exist, some of which focus solely on e-inclusion (Van Dijk, 2005). However the conceptualisation is often along the barriers of adoption. For instance, Van Dijk in his framework sees access as impeded by for barriers such as Motivational access (disinterest in technology), material access (lack of actual ICT material), skills access (lack of digital skills, low user friendliness of the gadgets or lack of social support groups) and finally user access (speaking to uneven spread of opportunities across societies). This framework is similar to Helsper's (2008) framework, which looks at digital disengagement as determined by either external factors that are often beyond 
the user abilities such as the low-income levels or poor infrastructure. Helsper's four classification include: ICTs access, skills, attitudes and extent of engagement. There is plenty of research that speaks to the ICTs and the link it has with socio-economic development of the people (Aker and Mbiti, 2010; Donner, 2008; Morawczynski, 2011; Komen, 2016), however despite these evidence, many are digitally disengaged but socially engaged (Helsper, 2008). The role of lifestyles and life changes has also caught attention of many scholars as key influencers of adoption of technology (Haddon, 2004; Verdegem, 2011). It has been noted so far that mobile phone influence is diverse as users in different contexts appropriate the technology differently to meet their needs (Goggin, 2011; Katz and Aakhus, 2002; Ling, 2007; Molony, 2010). Domestication theory provides a useful framework to understand interactive communication technology use in the context of the user needs and ability to manipulate technology (Silverstone, et al., 1992). The key tenets of domestication theory are: appropriation (Possession and ownership), Objectification (meaning and symbols), incorporation of mobile phone in older people's everyday life and conversion (unintended uses). The underlying assumption of domestication of technology theory is that users shape the nature, scope and functions of technology within their contexts (Haddon, 2003). Because of its context specific process, domestication is a process interweaved and shaped by values, type of life and identity of user and aspirations (Haddon, 2001; Ling, 2004; Katz Methodology.

This study was a multi-step study using descriptive research design. Firstly, all the 40 participants all retired from formal service and belonging to a group were given a questionnaire to get the general demographics and overview of types of phones used, and uses in general sense. The questionnaire responses were then analysed and a second round of data collection followed where out of the responses, further interviews were asked the same group to shed more light on what they had indicated in the questionnaires. Notably although the participants were free to withdraw at any stage for whatever reasons, all of them completed the questionnaires. The group interviews were later conducted on the second week, audio recorded, transcribed and analysed theoretically. Emerging themes were also noted for discussions. The questions ranged from uses, phone applications they preferred and why, and how they valued or not mobile telephony in their everyday life. All the 40 participant had phones, 38 of them with smart phones while 2 had ordinary phones-not internet enabled. All were retirees from 60 plus years of age. In terms of phone appropriation, all the participants positioned their phones at close proximity, their shirt pocket, handbag for ladies or by hand, trouser pocket, on their lab while driving for some, next to their study table or hanged from the neck. None of the phones was on silent mode.

\section{Data Analysis}

The uses patterns were explored through the descriptive statistics, to identify the uses, level of use, how the tenets of domestication theory were experienced such as appropriation, objectification, incorporation and conversion. These tenets were later cross examined using the demographics, such as socio-economic status, education or 
literacy levels and whether the design and applications or features of the mobile phone were experienced differently. These were then presented by pie charts, bar charts and narratives as follows

\section{Findings}

\section{Mobile phone incorporation}

All the participants aged 60 plus owned mobile phones and used them. Prominent use was contacting family and friends, with asking for help as the main content of calls or texts. The prominent uses were voice calls, followed by texting, use of alarms, calendar with very few uses around camera and playing games over the phone. When asked further what calling for help entails, the following had this to say,

'For me I rarely call but when I do I just call my children to send me money so that I can purchase my Diabetes drugs, I am sick you know' (Participant 263 , father of 4 and grandfather of 2 from Bungoma county).

These sentiments were echoed by many. However, participant 10, 68, a mother of 7 and grandmother of 5 said, 'There is no need of calling. I just text, or even send a please call me, my children will know automatically that I need help. They then call back to find out what it isthe joy of having many children. Participant 10, put little hope in her children or grandchildren to help and instead she lay much hope in her business associates and planning for all manner of eventualities.

Another participant explained why she uses SMS,

As for me I just call my business associates, say we have a meeting or one of us is unwell, we then arrange to meet at that person's a house but mostly I call when I need things delivered or when there is a business discussion around how to increase my income... if you don't work hard, these children will soon abandon you ', said, Participant 7, 73 a retired banker).

The study also reveals much deeper needs driving adults to texting: to connect and belong. Health was a concern for many as seen in Second participant's case. The realisation that age brings challenges such as isolation or abandonment as presented by Joshua. The mobile phone was used to meet the psychological need of connecting with friends and family (see Petrovcic et al, 2015; Nimrod, 2015; Oskman, 2006) and as a way to guard against possible isolation or abandonment by the same children or family.

\section{Mobile phone objectification-meanings and symbols}

The majority of the participants 35 claimed to find meaning in the utility of the phone particularly features that met their needs. For instance, many saw mobile phone as light because of the spotlight affordance that the phone provided, while others saw no need to own a wrist watch since the phone could act as a watch too. To the businessmen and women, the calculator was the most preferred feature as it helped them do their math and avoid being conned. Yet for others, the mobile phone was a memory reference but 
also a trigger or alert for them to do a predetermined task such as walking, going to the market, waking up or taking medications. Mobile phone stood as an alarm.

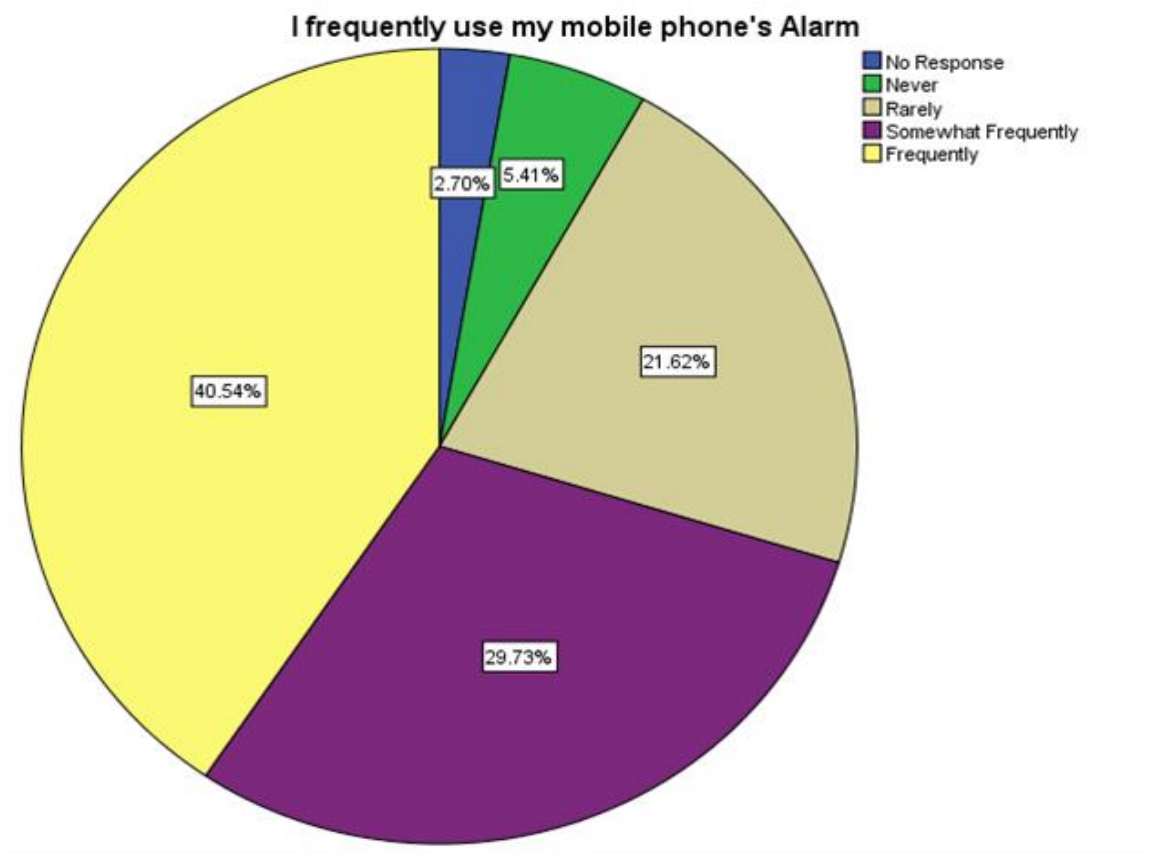

When asked why they needed the alarm that much, the following responses were noted,

'When you get old you begin to forget things, and sometimes you even oversleep; so for me, the alarm wakes me up to take my high blood pressure medication, but also disturbs me at times' (Participant 18, a female aged 78)

Researcher: What do you mean?

Participant 18 continues: 'What do I wake up to do or go? I am no longer working and I do not have to clock in at anybody's office, so when this thing (pointing to the phone) goes off, I have certain annoyance even though I know I can save my life too by taking my medication.' There was a quick rejoinder from a male participant, I

'As for me, my alarm is so annoyingly loud. I have tried to make it quiet but haven't succeeded, but also this small phones are not helping my big thumbs, see (he shows the researcher his size of thumbs which covers almost half of the phone) so how do I even press the right thing'? (Participant 4, aged 77, retired high school teacher)

The alarm and calculator served the need for physical as well as practical advantages, but such benefits are not easily gained as earlier noted by Hocky( 2012) that the older adults often 'exhibit insufficient mobile literacy' namely the 'skills needed to effectively use mobile or handheld devices' (P. 109). In addition to skills, matters of design of mobile technology also mattered. Mobile technology that paid no or little attention to older adults' specific needs, as opposed to agile younger people whose muscle flexibility is at the core, older adults in most cases have their muscles somewhat rigid at this juncture in life.

Mobile phone conversion-Unintended uses 

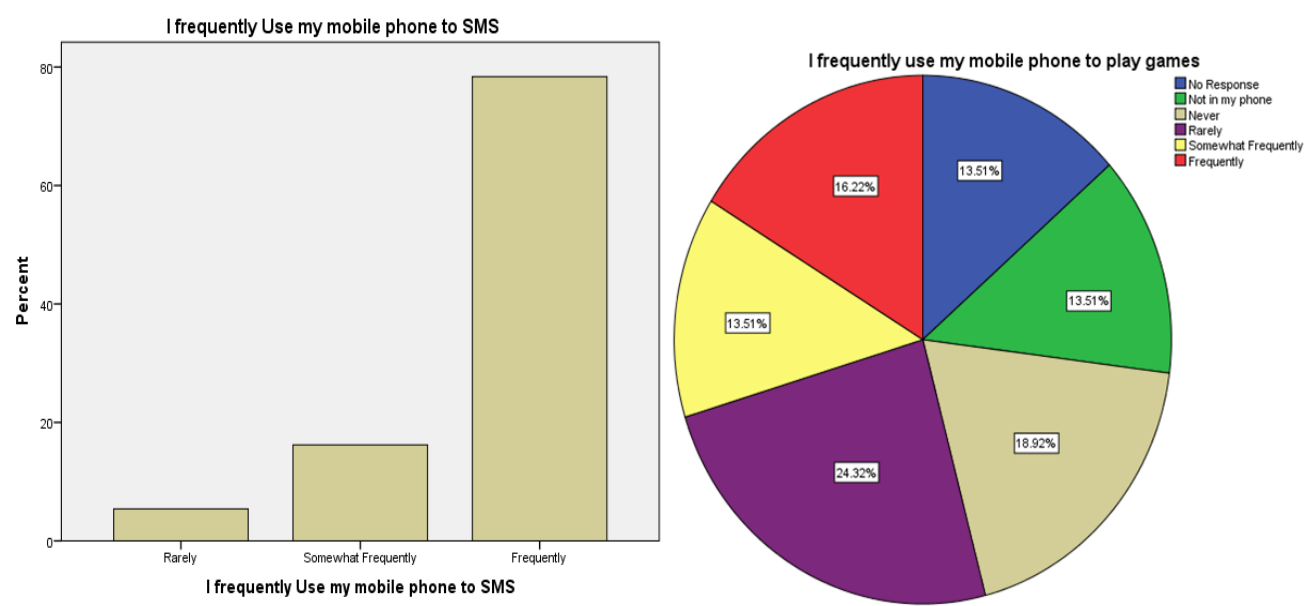

The majority of these participants fronted short message texts (SMS) as their widely used feature. This was in contrast with earlier studies (Kurniwan, 2008, Lenhart, 2010; Ling, 2008) that noted that older adults are less likely to text. Only a handful used their phone to play games and when asked why that was the case, this is what they said,

'Games are childish, why waste time on it' Participant 19, male aged, 67.

'I haven't even tried, you mean there is that function here?' Participant 20, grandmother aged, 70

'Why should I waste time playing something that has no reward?' it is not like betting? Is it? Participant 12 mother of 4, aged 66.

Even in old age, it appears economics are the driving force for people of Western to appropriate mobile technology.

The perception of mobile phone games were varied as seen in these three excerpts from the focus group interviews suggesting that one can only engage if there is a direct monetary benefit, whereas others were totally unaware, yet others dismissive of the feature. Mobile phone appears to be strongly tied to one's perceived benefits but also culturally annotated.

Having examined all the functions already incorporated in everyday life of these older adults from Western Kenya, the researcher wanted to know if they had a wish list. 


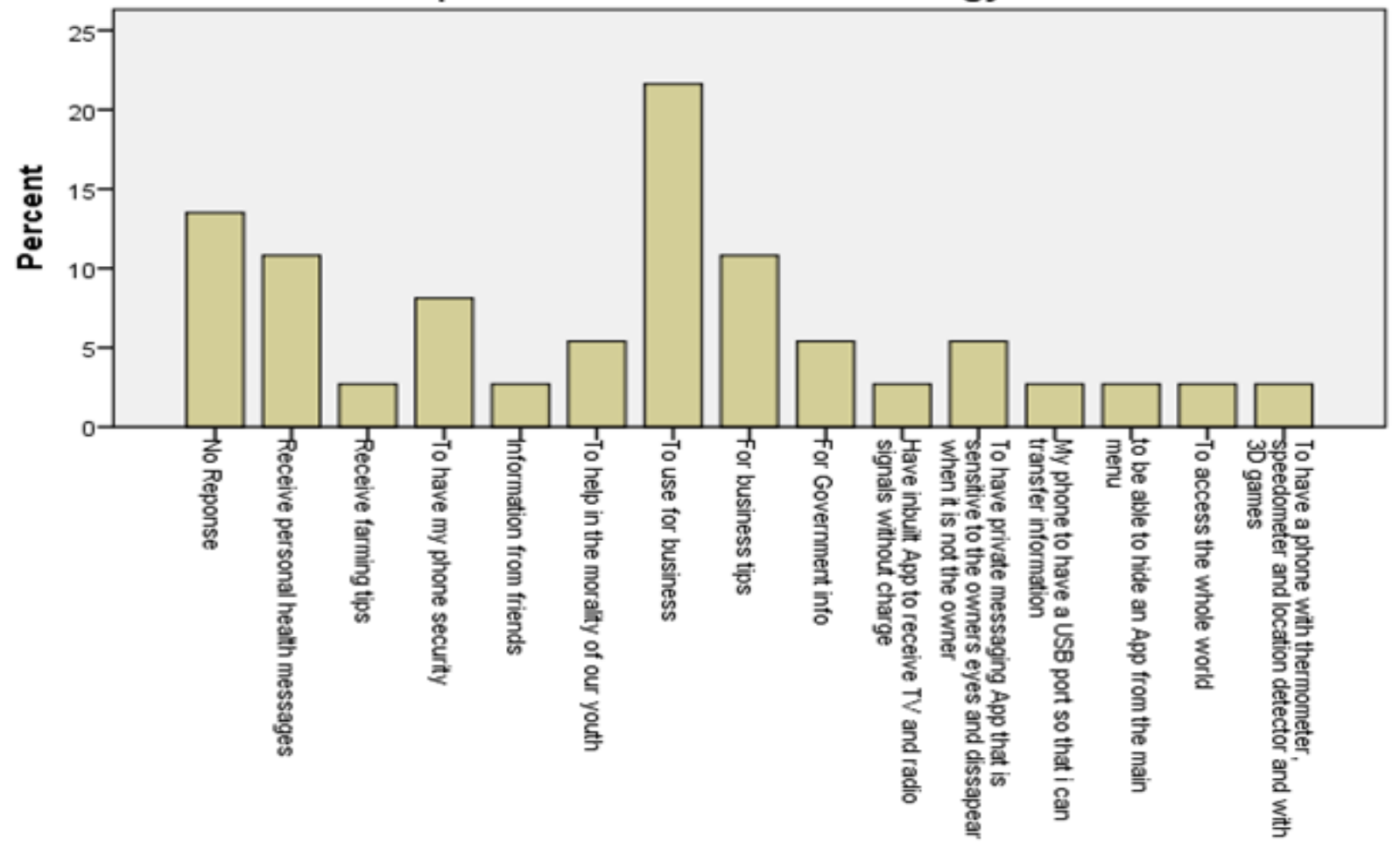

Many wanted a device that could facilitate business tips communication and not just the mobile money feature, this was followed by a category that chose not to respond. There is a larger group who wished to receive personal health messages. This can be explained by earlier comments from participants wanting to be woken up to take medication or reminded to take a walk. Asked what exactly they wanted in regard to personal health messages this is what they had to say,

'I want once I take my diabetes medication; the phone can read and tell me my sugar levels', (Participant 39, aged 80). 'I want some information immediately on my blood pressure, it should tell me when I need medication even before time, like warn me so I can rush home to take the medication' (participant 14, aged, 68)

'My doctor says I am overweight, can the phone read and tell me how much calories I need to burn like when I hang it or press it somewhere like my chest'? (Participant 9, male aged, 71, retired office administrator).

\section{Discussion and conclusion}

This study is underpinned by Nimrod's (2016) observation that older people use mobile phones extensively, yet little is known about their relevant domestication. As noted by early domestication of technology theorists (Haddon, 2002; Silverstone, Hirsch \& Morley, 1992) uses of such devices are often a negotiation between users, context and other artefacts. As has been noted in this study it would be prudent that over and above, users, contents and artefacts that older people's previous engagement or means of livelihood also determine how much of mobile telephony affordances they can exploit. For instance, persons such as Participant 773 a retired banker who noted that he would 
call his business associates for a meeting but mostly to ask for deliveries to be done. For participant 7, function affordances such as calling, texting and mobile money plus his wider social networks of business networks would present mobile phone as an assemblage rather than just a call and receive mode common for many his age.

Unlike earlier studies that fronted SMS function of the mobile phone as less used among older adults (Kurniwan, 2008, Lenhart, 2010; Ling, 2008) this study found that the majority of the older adults studied preferred SMS because it was cheap but also because it was closely tied to sending 'thank you' texts upon receiving goods or MPESA texts.

The question of how much use the older adults used mobile phone as per this study varied from the use patterns, health status of the respondents and the preferences asp was largely driven by their live dispensation. For instance all those who had life threatening sickness such as non- communicable diseases preferred to set alarms on their phones to remind them on when to take their medication, yet to others the alarms was a disruption, when they felt there was no need to wake up early no more stating, 'what am I waking up to?' as stated by Participant 18 earlier referred to. This speaks to a larger debates of purpose, when one feels they have lost their sense of purpose or there are no more demands upon them such as 'be in the office by such and such a time, report, then that motivation is taken away, they find it hard to fill the new found freedom with anything meaningful. I am sure the psychologists have something to say to this phenomenon. Although the mobile phone has many other functions, its affordance as a multi-media device was not fully exploited by the older adults. For instance the ability to play games, or take photos and the like was not highly spoken of. With some stating categorically that those provisions were 'child's domain' as ably said by Participant 19 who record 'games are childish, why waste time on them?' This statement in a sense resonates with the cultural often direct meaning of games to mean play, and play in the majority of African contexts is seen as for children. To ask older adult whether they played games on their phones even though their phones had such provisions fell short of an abuse.

Although the mobile phones were highly welcome additions in the lives of older adults, in this study we observe that challenges also abound particularly in matters of design with many of them complaining of smaller phones, smaller font sizes, and so much lighting on the screen which they complained affected their failing eyesight..

Mobile telephony use among older adults in Western Kenya hence showed that mobile technology domestication indeed depended on many factors and that the influence of mobile telephony on the lives of older persons was subject to specific realities of each older adult, however there were common areas of celebrations such as being able to call their social support networks, with others feeling the mobile phone was more of a closer family member because of its ever presence, yet also concerns on the fact that the same mobile phone seemed to have driven family members away from them, they use mpesa and just visit home rarely they said. In conclusion the subject of inclusion or exclusion is more real among older adults now more than before with 
conventional beliefs now being challenged with the domesticated use of mobile telephony among older adults across contexts.

\section{Limitations of the study}

This study only focused on older adults who have formal employment and hence their views on the utility of mobile phone past their retirement cannot be replicated across all older adults. Although this study did not specifically look at the internet enabled mobile phone and its strength in presenting the multimedia richness it was clear that the use of many functions that a mobile device can offer were not fully exploited by the older adults' group.

\section{Acknowledgement}

The researcher would like to acknowledge the financial grant given by Daystar University, Kenya, to carry out this study.

\section{References}

Chen, K., Chan, A.H.S., \& Tsang, S. N.H. (2013) Usage of mobile phones amongst elderly people on Hong Kong. In proceedings of the International Multi-Conference of engineers and computer scientists 2013 (Vol.2. 1-4). Hong Kong: IMECS

Dijk, J. V., (2005). The Deepening Divide, Inequality in the Information Society. Thousand Oaks, London, New Delhi: Sage

Friemel, T. N. (2014). The Digital divide has grown old: Determinants of a digital divide among seniors. New Media and Society. Retrieved from http://journals.sagepub.com/doi/abs/10-1177/1461444814538648-2019, November 13, 2019

Helsper, E., (2008). E-inclusion: An Analysis of Social Disadvantage and the Information Society, Communities and Local Government, London. Retrieved from

http://eprints.lse.ac.uk/26938/1/ libfile REPOSITORY Content Helsper,\%20E Digital \%20inclusion Helsper Digital\%20inclusion 2013.pdf $11^{\text {th }}$ march, 2019

Hassan, H., \& Nasir, M. H. N. (2008). The use of mobile phones by older adults: A Malaysian study. SIGACCESS Newsletter, 92, 11-16

Hockly, N. (2012). Digital literacies. English Language Teachers Journal, 66(1), 108-112

Joe, J., \& Demiris, G. (2013) older adults and mobile phones for health: A review. Journal of Biomedical Informatics, 46, 947-954

Kurniawan, S. (2008) Older people and mobile phones: A multi-method investigation. International Journal of Human-Computer Studies, 66, 889-901

Lee, R.Y.W., \& Carlisle, A.J. (2011) Detection of falls using accelerometers and mobile phone technology. Age and ageing, 40, 690-696

Lee, Y.S. (2007) Older adults' user experiences with mobile phones: Identification of user clusters and user requirements 
Lehart, A. (2010) Cellphones and American adults. Retrieved from

http://www.pewinternet.org/Reports/2010/mobile-access-2010.aspx March 13, 2020

Ling, R (2008) Should we be concerned that the elderly don't text? The Information Society, 24, 334-341

Livingstone, S. and Helsper, E., 2007. "Gradations in e-inclusion: Children, young people and the digital divide", New Media \& Society, [Online], vol. 9, no. 4, pp. 671-696. Retrieved from:

http://eprints.lse.ac.uk/2768/1/Gradations in digital inclusion \%28LSERO\%29. pdf 25 June2019

Massimi, M., \& Baecker, R. M. (2007). An empirical study of seniours' perceptions of mobile phones as memory aids. In A. Mihailidis, J.Boger, H.Kautz, \& L. Normie (Eds.), Technology and the aging-Selected papers from the 2007 International Conference on Technology and Aging(pp.59-66).Amsterdam, the Netherlands: IOS Press

Nimrod, G. (2018). Technophobia among older internet users. Educational Gerontology, 44:2-3, 148-162, DOI: 10.1080/03601277.2018.1428145. January, 24, 2018

Nimrod, G. (2016). The Hierarchy of mobile phone incorporation among older users. Journal of mobile media \& Communication, 4(2); 149-168

Oksman, V. (2006). Young people and Seniours in Finish' mobile information society' Journal of interactive media in Education, 2, 1-21

Petrovcic, A., Fortunati, L., Vehovar, V., Kavcic, M., \& Dolnicar, V. (2015) Mobile phone communication in social support networks of older adults in Slovenia. Telematics and Informatics, 32(4), 642-655.Retrieved from http://sciencedirect.com/science/article/pii/S0736585315000179, January, 24, 2018

Shultz, R., Wahl, H.-W., Mathews, J,T., Dabbs, A.D.V., Beach, S.R., \& Czaja, S.J. (2014)Advancing the aging and technology agenda in gerontology. The Gerontologist. Retrieved from https://academic.oup.com/gerentologist/articles/55/5/724/2605219

Silverstone, R., Hirsch, E., \& Morley, D. (1992) Information and Communication Technologies and the moral economy of the household. In R. Silverstone \& E. Hirsch (Eds.), Consuming technologies: Media and Information in domestic spaces (pp.1531). London.UK: Routledge

Smith, A. (2014) Older adults and technology use. Pew Research Centre. Retrieved from http://pewinternet.org/2014/04/03/older-adults-and-technology-use

Vedegem P., 2011. "Social media for digital and social inclusion: challenges for information society 2.0 research \& policies", Open Access journal for a Global Sustainable Information Society, [Online], vol. 9(1) 